\title{
PALABRA DE PÍCARO: LA REPRESENTACIÓN DISCURSIVA COMO REPRESENTACIÓN DEL MUNDO
}

\author{
Fernando Cabo Aseguinolaza \\ Universidad de Santiago de Compostela
}

La ocasión de recordar y rendir homenaje al gran Mario Valdés resulta muy apropiada para aproximarse a una cuestión que no le será ajena: la que lleva a relacionar a Velázquez con la picaresca como medio para subrayar la radical modernidad de esta última. Esta concepción de la picaresca como expresión privilegiada de un nuevo paradigma literario ha sido apuntada con cierta frecuencia por los estudiosos, aunque me atrevería a decir que muy pocas veces con la rotundidad necesaria y la capacidad para extraer de cllo todas las consecuencias del caso. Entre las excepciones es de justicia recordar, por ejemplo, los nombres de Peter N. Dunn y Michel Cavillac. Y quizá ahora, en un ejercicio inscrito en el viejo tópico de ut pictura poesis que utilizará como principal vehículo los análisis de Ortega y Maravall, pucdan contribuir estas líneas a desarrollar algunas sugerencias en este sentido.

Una de las razones que pueden contribuir a entender la timidez a la hora de situar la picaresca en la esfera de lo moderno es una cierta insuficiencia del método historiográfico dominante, que sigue empeñado con frecuencia en no admitir lo que por cierto es ya moneda común en el ámbito científico; csto es, que la ciencia tiene que ver con datos pero también con conceptos y con un imprescindible marco teórico que dé sentido a todo ello. Y que tanto o más importantes que los hechos son las nociones que los sitúan en una determinada perspectiva y hacen posible su interpretación. Cuando esto se olvida corremos el riesgo, tantas veces confirmado, de reducir la novedad a un sinnúmero de fuentes y antecedentes. De no percibir, en suma, lo que hay de verdaderamente significativo en un cierto fenómeno literario y cultural. Quizá no sea del todo improcedente traer aquí a colación la analogía con el concepto biológico de emergencia, que busca dar cuenta del fenómeno según el cual en los niveles superiores de integración de un sistema surgen características que no se podrían haber predicho, ni tampoco explicar a posteriori, a partir del conocimiento y análisis de los niveles inferiores.

Esto sucede de manera aún mucho más radical en el terreno de las humanidades y de la historia, en donde los procesos de interpretación, valoración e incluso involucración ideológica son tan 


\section{PALABRA DE PÍCARO: LA REPRESENTACIÓN DISCURSIVA}

importantes, no ya como elementos disturbadores, sino como aspectos esenciales de lo que en cada caso se halla en cuestión. Recordemos una vez más que la picaresca no es una noción contemporánea al Lazarillo, el Guzmán o el Buscón ni tampoco reductible a esas obras como textos. Si hablamos de picaresca cstamos refiriéndonos al contacto entre tiempos diversos: el tiempo de la escritura de las obras, también la tradición implicada en ella, y los otros tiempos en que aquellas se han interpretado, leído y, por qué no, utilizado literariamente. Sólo así se vuelve tangible la conciencia de novedad y pertinencia cultural y la insinuación de un cierto imaginario, digamos, emergente.

Pensemos, por ejemplo, en el celebérrimo ensayo de Francisco Rico La novela picaresca y el punto de vista, donde, valiéndose, como reconocería más tarde, del concepto braudeliano de la longue durée, finge su autor situarse a la altura histórica de los textos, pero con el privilegio añadido de contar metodológicamente con el horizonte de su continuidad. Es decir, utilizando las consecuencias atribuidas a la la radicalidad en el uso del punto de vista por parte de los relatos picarescos (el surgimiento de la novela realista clásica) como clave interpretativa de los orígenes. Un procedimiento, por cierto, no muy alejado de la circularidad perspectivística atribuida a las novelas de pícaros. Acaso se nos olvida que en las páginas preliminares del ensayo se aproxima y, al tiempo, contrapone la picaresca nada menos que al nouveau roman. Y, de hecho, la postdata en la que se revisará alguna de las tesis fundamentales del libro justifica tal proceder -csto es, el análisis de la picaresca en el marco general de la novela, entendida ésta según el paradigma realista decimonónico- con el argumento de que «al carecer la novela de una forma específica e inequívoca, su aparición tardía y las vicisitudes de su existencia [...] casi hacen imposible comentar una novela sin atender simultáneamente a toda la historia del género»'.

Otros ejemplos, de orientación contraria, nos llevarían a considerar no ya la interpretación de la picaresca según la pauta de su porvenir, sino la atribución a ella de un valor a la luz de los intereses presentes. Intereses, pienso ahora, literarios. En otro lugar he estudiado la compleja y extraordinariamente creativa relación de algunas de las primeras obras de Cela con la picaresca ${ }^{2}$. Pensemos en el Pascual Duarte, que, si bien nunca se reclama picaresco, fue recibido con notable unanimidad por los reseñadores de primera hora como una actualización de la picaresca española del Siglo de Oro. En esta circunstancia no resulta indiferente la estética falangista imperante en muchos de estos recensionistas ni el evidente desco de redefinir, a la altura de 1943, el tiempo histórico literario nacional a través de la conexión entre la nueva narrativa de postguerra y el pasado más glorioso de las letras patrias. A lo que ha de añadirse el entendimiento de la picaresca como manifestación sobresaliente de literatura de acción, y no intelectual ni crítica. Esto es, la objetivación de una muy determinada posición estético-ideológica. Poco después, en el Nuevo Lazarillo, se apuntará ya de modo directo al referente picaresco, pero de una manera discrepante a la definida por los reseñadores del Pascual. De hecho, la acogida oficiosa será mucho menos encomiástica y, lo que resulta más sorprendente, la apelación a la picaresca será ahora entendida cn algún caso como derrotista e impropia de la nueva literatura. Cela había recurrido a la lógica del apócrifo, a la reivindicación de un pasado apócrifo en el sentido machadiano, para hacer de la picaresca un factor de extrañamiento.

Con todo esto en mente, y hasta admitiendo el pecado filológico del anacronismo, sin el cual, por cierto, la literatura resulta incomprensible, me gustaría desarrollar algunas observaciones, seguro que discutibles, acerca de la peculiaridad de lo que hoy llamamos picaresca. Fundamentalmente se referirán al fenómeno de la palabra del pícaro: esa inusitada irrupción de discursos extensos, muy complejos literaria y retóricamente, y fundamentalmente indeterminados, esto es, propiciadores de interpretaciones distintas. Mirados con ojos de hoy, parece difícil negar que a partir del Lazarillo

1.- Francisco Rico, "Puntos de vista. Postdata a unos ensayos sobre la novela picaresca", Edad de Oro, III (1984), pp. 227-40, p. 228.

2.- Fernando Cabo Aseguinolaza, "Cela y la picaresca (apócrifa). Temporalidad literaria y referente genérico en el Pascual Duarte y el Nuevo Lazarillo", El Extramundi y los Papeles de Iria Flavia, XII (1997), pp. 151 - 188. 


\section{FERNANDO CABO ASEGUINOLAZA}

surja algo sustancialmente distinto a lo conocido con anterioridad e irreductible a lo previa y contemporáneamente frecuentado, sea la tradición menipea, las facecias folclóricas o los elogios paradójicos. Y resulta muy tentador entender esta cuestión a la luz de Velázquez, el creador al que Ortega identificó con una fauna excepcional de personajes variopintos, entre los que tanto sobresalen, pongamos por caso, un Pablillos de Valladolid, gesticulando y declamando sobre un fondo desaparecido, o el llamado don Juan de Austria, indecorosamente vestido a la soldadesca y rodeado de armas y otros utensilios militares ya privados de cualquier función verosímil. La coincidencia de su trayectoria vital (1599-1660) con el período de vigencia del relato picaresco como tal, si tomamos como hitos el Guzmán y el Estebanillo e incluimos en ese lapso a un Lazarillo vivificado por el calor del éxito de quienes más de una vez lo tomaron como referencia, no puede ser, en efecto, más sugerente.

Lo cierto es que la novedad que Ortega atribuye a Velázquez en el terreno específico de la pintura se aproxima mucho a una de las visiones más influyentes a la hora de caracterizar la picaresca como noción historiográfica. Escribía el filósofo madrileño el año 1943 en su Introducción a Velázquez: «El arte era ensueño, delirio, fábula, convención, ornamento de gracias formales. Velázquez se pregunta si no será posible con este mundo, con la vida tal cual es, hacer arte: un arte, por tanto, totalmente distinto del tradicional, en cierto modo su inversión» ${ }^{3}$. Esa inversión es la que lo conduciría, harto de lo poético, a la prosa, de acuerdo con los términos de la metáfora orteguiana. Es evidente que el vocablo que se siente merodear en torno a estas caracterizaciones es el de realismo. Como el traqueteado realismo que ha servido una y otra vez, desde sus principales paladines en el siglo XIX hasta Giménez Caballero, Lázaro Carreter o Rico, para sustanciar -cierto es que con muy diferentes perspectivas- la novedad asociada a los relatos de pícaros. Resulta interesante comprobar, sobre todo, cómo en los dos casos confluye la atribución del realismo con la orientación invertida respecto a los cauces dominantes de la tradición previa, lo que llevará al entendimiento tan arraigado de la picaresca como contragénero.

Pero lo verdaderamente relevante es, sin duda, qué se entiende por realismo en cada uno de los casos concretos, puesto que, como es sabido, el acuerdo en este terreno es por lo general nulo. Ortega hace de ello además uno de los ejes de su análisis de la obra del pintor sevillano, y por ahí puede venir la pertinencia para nuestras propias consideraciones. El punto de partida para todo ello es de apariencia paradójica desde el momento en que se sustenta sobre dos tesis que se dirían irreconciliables. Aventura de un lado el filósofo una tendencia general en la evolución de todo ciclo artístico que lleva a un predominio progresivo de las "formas constructivas" sobre las "formas naturales" del objeto, identificadas estas últimas con su presencia más humilde y cotidiana, de modo que, cuando dicho predominio se convierte en tiranía, acaba imponiéndose la necesidad de una ruptura que devuelva la atención y el respeto hacia las formas propias del objeto. Esta inversión de la tendencia manierista sería el realismo, cl cual, en consecuencia, tiene en su origen una determinación, diríamos, reaccionaria. De segundo grado, ya que exige una tradición previa a la que oponerse. En la tesis orteguiana se adivina la antinomia epistemológica entre subjetivismo y objetivismo, que tanta importancia tiene en la teoría estética de Ortega desde sus primeras formulaciones. De ahí que no sorprenda la segunda de las tesis, según la cual arte y realidad son por principio incompatibles, lo cual es también uno de los principios de continuidad de su pensamiento en este sentido. Pero quizá haya que expresarlo mejor. No es tanto que exista una incompatibilidad entre ellos, como que el arte se basa en el principio de desrealización ${ }^{4}$.

3.- El texto se publicó por primera vez en alemán el año 1943 y sería después recogido en versión española en Papeles sobre Velázquez y Goya (1950). Cito según las Obras completas, tomo VIII, Revista de Occidente, Madrid, 1962, p. 483.

4.- Para un tratamiento particularmente interesante de la cuestión, véase la sección tercera del libro de Rafael García Alonso, El náufrago ilusionado. La estética de José Ortega y Gasset, Siglo Veintiuno, Madrid, 1997. 


\section{PALABRA DE PÍCARO: LA REPRESENTACIÓN DISCURSIVA}

Velázquez no renuncia a desrealizar, mas sí la picaresca, de acuerdo con la concluyente opinión del autor de La deshumanización del arte sobre estos relatos: «es un arte, y aquí hallo su mayor defecto, que no tiene independencia estética; necesita de la realidad fuera de ella, de la cual es ella crítica, de la que vive como carcoma de la madera. La novela picaresca no puede ser sino realista en el sentido menos grato de la palabra. Lo que posee de valor estético consiste justamente en que al leer el libro levantamos a cada momento los ojos de la plana y miramos la vida real y la contrastamos con la del libro y nos gozamos en la confirmación de su exactitud. Es arte de copia»" Afirmación en sí misma discutible, pero que destaca la necesidad de reparar en cómo se entiende, ad contrarium, el realismo velazqueño y en qué medida es o no iluminador para el caso nuestro. Por otra parte, el hecho de que el texto que acabo de citar fuese publicado por primera vez en 1915, al calor de "Ensayo de estética a manera de prólogo" y de las Meditaciones del Quijote, y que se reeditase en el segundo volumen de las Obras completas en 1946, en los años en que dedica Ortega su atención a Velázquez, no deja de ser significativo; y hasta podría llevar a enfrentar, en la teoría orteguiana, la pintura del sevillano con la picaresca como exponentes de dos formas de concebir el realismo: una con toda la legitimidad de lo artístico por implicar el paradójico principio de la desrealización, la otra lastrada por un concepción vicaria de la representación, que la anularía como arte.

Es innegable, por otro lado, que el arte amanerado, frente al que supuestamente reaccionaba Velázquez, implica también la desrealización. Lo que habrá que buscar en el pintor será, entonces, una forma peculiar de cumplir con este mismo designio desrealizador pero con resultados valiosos. Eso es lo que se esfuerza en mostrar Ortega. La peculiariadad de la desrealización velazqueña se fundamentará en un proceso de reducción (y no evito las connotaciones fenomenológicas del término) que conduce al énfasis sobre algunos de sus aspectos, prescindiendo de otros superfluos asociados a la tradición. Describe esto el filósofo como «la retracción a la visualidad pura» que implica el rechazo de lo corpóreo y de lo que llama «datos táctiles». Resulta así que el pintor reduce la realidad a su fantasma, a su apariencia, al momento de presentársenos por primera vez. Así se entiende la caracterización del método velazqueño como un «convertir la realidad en permanente sorpresa».

¿Qué podría haber de todo esto en la picaresca? Por de pronto hay una semejanza en lo que se refiere a la posición que tradicionalmente -desde finales del XVIII- se le ha asignado a los relatos de pícaros como forma contragenérica, esto es, contrapuesta a las tendencias digamos idealizantes que se ha acostumbrado identificar con los relatos de caballerías, pastoriles y bizantinos y la que Ortega atribuye a Velázquez de ruptura «con aquel mundo convencional y fantástico» de sus antecedentes pictóricos. Pero sin duda podemos dar con otro aspecto que nos conduce a una analogía más provechosa. Me refiero concretamente a la propuesta orteguiana de reconocer en el retrato el principio de la pintura de Velázquez? ${ }^{7}$ El retrato es, de un lado, individualización, que precisa, pues, de una perceptible ruptura con la convención heredada, pero, de otro, también exige, como segundo rasgo determinante, la captación del instante, la representación del acto en su hacerse, como gesto detenido en el borde mismo de su modificación, y que en consecuencia se aísla del movimiento aunque lo sugiera. En palabras del filósofo: «Perennemente están en el lienzo las figuras ejecutando su propia aparición, y por esos son como aparecidos. Nunca llegan a instalarse plenamente en la realidad y hacerse del todo patentes, sino que están emergiendo del no ser al ser, de la ausencia a la presencia» ${ }^{8}$. El primer aspecto, con ese ostensible apunte hacia lo que se entiende como realidad

5.- Obras completas, tomo II, Taurus y Fundación Ortega y Gasset, Madrid, 20(04, p. 228. El texto al que pertenece este fragmento se publicó por primera vez con el título de "Observaciones de un lector" en La Lecfura (diciembre de 1915) y se incluyó posteriormente en el primer volumen de El espectador (1916) bajo el epígrafe "Una primera vista sobre Baroja".

6.- Obras completas, VIII, p. 477.

7.- Obras completas, VIII, pp. 478 y ss.

8.- Obras completas, VIII, p. 630. 


\section{FERNANDO CABO ASEGUINOLAZA}

frente a la herencia convencional, lo resumía elocuentemente el Pinciano, según recordaba Maravall' al decir que el poeta que «remeda a la naturaleza es como retratador y el que remeda al que remedó la naturaleza es simple pintor». El segundo resulta, en cambio, algo más difícil de formular y, sobre todo, de trasladar al ámbito literario de la picaresca. Cabe, no obstante, tomar nota de algo, y es la indecisión o inacabamiento formal, que, subraya de nuevo Ortega, se atribuía a la manera del pintor sevillano ya en su propio tiempo.

Recordemos: reducción a lo visual, individualización, aislamiento de la actitud respecto de su secuencia de movimiento, precariedad de la finalización. A pesar del dictamen de Ortega sobre el realismo picaresco, no creo que resulte descabellado plantear a esta luz aquello que realmente resulta extraordinario en la picaresca: el haber abordado de una manera radical la representación como una representación de discurso. En cfecto, también en ese sentido lo que he llamado en otro momento "acto picaresco" es pura apariencia y da lugar a un fantasma en el sentido orteguiano. Hablaba éste de «ese momento de realidad que consiste en presentársenos», y en relatos como el Lazarillo, el Guzmán o, incluso, el Guitón o el Buscón encontramos, por supuesto que con distinta fortuna e intención, ese momento como gesto de discurso, que implica una sucesión de acontecimientos anteriores y posteriores, cuyo conocimiento se nos hurta. Son siempre acciones suspendidas en el tiempo y, por ello, indecisas en sus resultados (pićnsese en el Guzmán) y motivaciones. En este sentido los relatos de pícaros se convierten en retratos en donde la visualidad se torna discursividad. No olvidemos, por ejemplo, que La lozana andaluza se presentaba como retrato y tal decisión puede muy bien atribuirse a los dos factores que ahora estamos resaltando: la reorientación de la referencialidad y el sometimiento de la representación de un mundo a la representación de la palabra de unos personajes concretos.

Maravall aludirá al carácter de experimento que tienen los cuadros de Velázquez. Ortega había hablado de teorema. Creo que algo muy semejante se podría decir sobre los primeros relatos de pícaros, desde el Lazarillo hasta el Buscón. En los dos casos la ruptura con el convencionalismo idealizante o doctrinal no implica una mayor o menor relación con el entorno social o históricamente definido, sino una recomposición del concepto de representación. Por esa vía podría explicarse, por ejemplo, el papel desempeñado por el ilusionismo referencial en estos casos, que siempre tiende a ser socavado en su posibilidad misma. Nadie podría decir, en efecto, que Velázquez. niegue la realidad, pero, como también subraya Maravall, la naturaleza pictórica de sus cuadros se impone a cualquier pretensión de verismo ingenuo. Ahí están sus pentimenti, la evidencia de la pincelada, la radicalidad de la perspectiva e incluso el vigor no puramente mimético de las referencias intertextuales. Comenta Maravall en este aspecto: "Antes, los medios técnicos de la pintura trataban de desaparecer para dejar en el más puro estado posible al objeto representado. Ahora, se afirman ostensiblemente aquéllos, para obligarnos a considerar la pintura, y sólo a través de ella, en cualquier caso, se nos permite el acceso al natural» ${ }^{10}$.

En lo que a la picaresca se refiere, esa mediación enfática corresponde a la palabra. En efecto, es la palabra del pícaro la que se impone y hace patente por encima de cualquier referencialidad directa. Es palabra que se evidencia como tal, e incluso como pura palabrería. Y cuando digo esto 


\section{PALABRA DE PÍCARO: LA REPRESENTACIÓN DISCURSIVA}

En sí mismo esto constituye una novedad de un enorme calado, más allá de cuál fuera la intención concreta de sus autores. Y tiene su correlato en otros aspectos, entre ellos, de manera muy destacada, la forma de tratar la intertextualidad. De un lado, hay que contar con las alusiones internas a la serie picaresca que, entre otras cosas, traban relaciones entre sus personajes o muestran a sus protagonistas como lectores de esos precedentes literarios. Tambićn, por supuesto, hay que contar aquí los esfuerzos de emulación o contradicción entre unos y otros, claramente perceptibles, para no ir más lejos, en el arranque de las distintas obras. Pero, de otro lado, se aprecia otro uso de estas referencias que no implica tanto la conexión interna a una serie o tradición genérica ni una imitatio en un sentido clásico, sino un esfuerzo por valerse de esas alusiones para dotar de coherencia al relato y en ocasiones proporcionarle una mayor riqueza significativa e incluso capacidad irónica. En todos los casos la trabazón literaria se impone al cfecto ilusionista.

Pongamos un ejemplo: el de la célebre casa toledana adonde el escudero conduce sin demasiadas explicaciones a Lázaro, quien, a su vez, nos envuelve en un impagable juego de suposiciones y expectativas progresivamente frustradas hasta acabar en los más negros augurios sobre su futuro. El pasaje es lo suficientemente conocido como para que sean necesarios otros detalles. No obstante, prestemos atención a lo que constituye una especic de epifonema que cierra la somera descripción del aposento del nuevo amo: «Finalmente, ella parescía casa encantada». Se trata del único paso descriptivo en el relato entero de Lázaro. ¿Por qué, pues, esta detención en la oscuridad y lobreguez, desnudez y silencio de la casa? ¿Por qué acudir a encantada como adjetivo capaz de sintetizar el sentido de la descripción esquemática que hace el pregonero?

Por de pronto puede decirse que la imagen proverbial de la casa encantada, preparada con la mención de la «entrada obscura y lóbrega» y de la falta de cualquier otra «viva persona», resalta el silencio y apartamiento de la casa del escudero. Señalaba, en efecto, Covarrubias, podría ser que a la zaga del Lazarillo: «casa encantada, la que está cerrada y con mucho silencio, y la gente della escondida y recatada». En el Diccionario de Autoridades se reiteran los mismos rasgos - «la que está de ordinario cerrada, y sus moradores viven retirados, guardando notable recato, sin dar ni hacer ruido»-, que son ejemplificados precisamente con nuestro pasaje. Nótese además que cl silencio y cierre era de hecho lo que resaltaba el narrador. Alguna vez se ha supuesto incluso que la proverbialidad de la casa tendría su origen en cl Lazarillo. Sin embargo resulta muy tentador considerar la latencia en la comparación de Lázaro del eco de algunas célebres casas encantadas toledanas, que incrementa notablemente la riqueza connotativa del episodio, como por ejemplo la casa de Ercoles, de la que se subrayan en la Crónica sarracina «las llaves e los candados» con que estaba cerrada, la turbación que ocasiona a los que entran en ella y los malos presagios que encicrra para los entrometidos ${ }^{11}$. Pero más allá de las concretas resonancias toledanas, habría que considerar, como bien ha visto Antonio Armisén ${ }^{12}$, ciertas moradas alegóricas como la «triste morada del que muere porque muerte no le quiere» del Arnalte y Lucenda o la Casa de los Celos descrita en la Octava Rima (CXXXV, vv. 97-122) de Boscán. O aquella otra, la casa de la Mclancolía, a la que se referirá posteriormente Alonso de Ledesma en sus Conceptos espirituales y morales, dejando así constancia de la pervivencia de la carga semántica de estas viviendas: «Vive [la Melancolía] en una casa sola, grande, lóbrega, y antigua, tal que la goza de balde porque ninguno la alquilas ${ }^{13}$.

Lo que pueda haber de emblema o alegoría tradicional se pone al servicio de una palabra concreta y de una intención realista, aunque en el sentido complejo que estamos delincando. Cabría incluso aventurar una semejanza con la forma en que Velázquez trata las "historias" y

11.- Floresta de leyendas heróicas españolas, ed. R. Menéndez Pidal, 3 vols., La Lectura, Madrid, 1925, I, pp. 188-195.

12.- Antonio Armisén, Estudios sobre la lengua poética de Boscán. La edición de 1543, Universidad de ZaragozaPórtico, Zaragoza, 1982, p. 421.

13.- Alonso de Ledesma, Conceptos espirituales y morales, ed. E. Juliá, CSIC, Madrid, 1969, vol. II, p. 345. 


\section{FERNANDO CABO ASEGUINOLAZA}

los motivos mitológicos en su producción pictórica, aunque sólo sea en cuanto en los dos casos la trama simbólica heredada se utiliza al servicio de una estrategia representativa de signo completamente distinto. Acaso la implicada en el concepto de retrato: siempre se han relacionado los caracteres que articulan la representación de la célebre casa con la personalidad única y en acción del supuesto escudero que se sustancia en la precariedad de su vivienda. Mas también la estrategia retratística retrata al retratante, que es Lázaro. Pensando en trazar una nueva conexión con lo que atribuye Ortega a Velázquez, podemos recordar nuevamente sus palabras: «Es cierto que Velázquez, aun aceptando pintar mitologías, va a hacerlo con un sentido opuesto al que sus contemporáneos - pintores y público- buscaban en ellas [...] Para Velázquez es un "motivo" que permite agrupar figuras en una cscena inteligible» ${ }^{14}$.

La casa del cscudero no constituye, ciertamente, una mitología, pero sí implica una historia e incluso una resonancia alegórica presente en la conciencia de los lectores. Aun cuando se pueda insistir sobre las evidentes diferencias de cada caso, es claro que en ambos la rotundidad tradicional del elemento consabido se diluye para subordinarse a un modo representativo radicalmente nucvo en el que prima la constitución de un personaje, su individualización figurada: en nuestro caso a través de la valoración y apreciación del otro, el escudero, que se hilvana en una delicada estructura narrativa dependiente de ese personaje último, reducido a pura apariencia, que es el pregonero narrador.

Hay, siguiendo en esta línea, una preciosa observación de Peter N. Dunn ${ }^{15}$, la cual admite ser completada pro domo nostra. Y es que podría parecer, en efecto, que, por contraposición al carácter de figuras que tienen aquellos personajes que dan la réplica a Lázaro (ciego, clérigo, escudero...), el destrón se muestra indefinido, como mero sujeto pasivo, hasta que va emergiendo paulatinamente como personaje para acabar convertido él también en figura: la del cornudo consentidor que se adivina en los últimos párrafos del relato. Pero, claro es, con el elemento añadido de lo que se nos ha ido contando sobre él y, en especial, del conocimiento inevitable de que sobre esa figura se yergue la fantasmática presencia del narrador, verdadero objeto del retrato. No olvidemos que esa voz que dice yo corresponde también al único personaje que tiene nombre frente al distanciamiento anominal de los otros. Sin embargo sería un error el suponer que Lázaro es el único que trasciende el prejuicio de lo consabido que define a la figura. Su apariencia como palabra, inevitablemente compleja, no deja intacta la intrascedencia a la que, en principio, parecerían condenadas las supuestas figuras que le sirven de amos. No sería excesivo el apuntar a una verdadera desconstrucción o puesta en acción del estatismo figural de personajes como el ciego, el escudero o el clérigo de Maqueda. Mucho se ha escrito sobre los dos primeros y algo menos sobre el último. Detengámonos brevemente en él a través de un par de notas.

Podríamos quedarnos, en efecto, con la mera mención del carácter tradicional de su avaricia, refrendada fácilmente con un centón de menciones mejor o peor traídas a la ocasión, pero no hay por qué quedarse en ello. Así, para poner un ejemplo, la elusiva observación sobre la laceria del religioso «no sé si de su cosecha era o la había anejado con el hábito de la clerecía» podría leerse, especialmente cn su primera parte, a la luz de la reconocida abundancia de conversos en Maqueda (así lo explicita Covarrubias) y del hecho de que, según recuerda Shiplcy ${ }^{16}$, el arzobispo Silíceo hubiese manejado la abundancia de conversos entre el clero de pueblos y villas toledanos como un argumento a favor de la imposición de los estatutos de sangre. No olvidemos que la polémica sobre los estatutos tuvo Toledo como centro a partir del que Silíceo había promovido en 1547 para su catedral -la misma en la que Lázaro vio al escudero oír misa-.

14.- Obras completas, VIII, p. 481.

15.- Peter N. Dunn, Spanish Picaresque Fiction. A New Literary History, Cornell UP, Ithaca y Londres, 1993.

16.- George A. Shipley, "Lazarillo and the Cathedral Chaplain: A Conspirational Reading of Lazarillo de Tormes, Tratado VI”, Symposium, XXXVII (1983), pp. 216-241, p. 229. 


\section{PALABRA DE PÍCARO: LA REPRESENTACIÓN DISCURSIVA}

O pensemos en esta otra observación que deja caer el narrador: «Pues ya que comigo tenía poca caridad, consigo usaba más». En ella cabe entender una concordancia irónica con el dicho «La caridad ordenada empieza de sí mismo»" ${ }^{17}$. El comentario de Lázaro va más allá del simple chiste, ya que se sugiere un entendimiento torcido de la caridad por parte del clérigo y esta, junto con la fe, es la virtud más destacada tanto por los erasmistas como por otros reformadores cristianos. Muy al caso parece venir, por ejemplo, el comentario que con respecto a este mandato se contiene en Doctrina cristiana: «ANTRonjo: Mucho me marauillo desso que dezís. ¿Cómo, no dize Dios que la charitas bene ordinata incipit a seipso? ARÇOBJSPO: Assí lo he oydo; pero no sé que lo diga Dios, sino que los hombres que son amadores de sí mesmos se lo leuanten; y aunque podría tener buen sentido, no quieren ellos sino darle el peor que pueden. ¿No vistes qué donosa regla? No cierto de charidad, sino de carnalidad» ${ }^{18}$.

Y la caridad es comúnmente destacada en este tiempo como elemento distintivo del verdadero cristiano tanto en la doctrina como en la práctica ${ }^{19}$. Y si pasamos más adelante nos encontraremos con otros pasajes que no se dejan reducir tampoco a meros comentarios deudores de una tradición. Me refiero, por poner un último ejemplo, a la mención de que la encargada por el cura de su restablecimiento tras el tremendo garrotazo era «una vieja que ensalmaba», puesto que, dando por hecho su tradición y presencia frecuentísima en la literatura de la época, su importancia doctrinal -nada desdeñable, por cierto- suele quedar preterida. De nuevo en la Doctrina cristiana, Juan de Valdés se detenía a condenar a los ensalmadores, propuestos nada menos que como ejemplo destacado de quienes toman el nombre de Dios en vano ${ }^{20}$. Y aún más radical será Pedro Ciruclo, quien señalaba: «qualquiera hombre o muger que por estos ensalmos quiere sanar $[\ldots]$ tiene pacto secreto de amistad con el diablo enemigo de dios, y de los hombres. Este es gravíssimo peccado de ydolatria contra el primero mandamiento. $\mathrm{Y}$ es apostasia contra la religion christiana que prometio con el baptismo»"

En fin, no se trata ahora de sostener tesis ninguna a propósito de la intención o la autoría de la obra, sino simplemente de apuntar la complejidad y sutileza del decir de Lázaro, a través del cual se delinea su retrato. No olvidemos que la dimensión que adquicren las supuestas figuras que jalonan el discurrir vital del hijo del molinero emerge de la palabra de este. $A$ la vez que la imagen (aparición o fantasma) del Lázaro cornudo depende de la palabra representada sobre la que se sostiene en equilibrio inestable.

En vista de ello, no debe extrañar que Maravall, al contrario de Ortega, llegase a relacionar en un cierto momento el principio velazqueño del retrato con la novela picaresca contemporánea y su uso de la primera persona. Sugiere así el elemento que algo después desarrollarían Fernando Lázaro y Francisco Rico: «La novela nos cuenta lo que en el mundo pasa, sólo que el nuevo descubrimiento literario consiste en advertir que eso que pasa en cl mundo no es accesible en su realidad concreta más que a través de un órgano de visión muy específico: ese órgano no es otro que la vida humana» ${ }^{22}$. Evidentemente un principio de modernidad innegable, pero que no queda del todo bien explicado si nos limitamos a saludarlo como innovación y no nos planteamos las trampas semióticas que puede encerrar. Pensemos, por ejemplo, en la ya tradicional constatación sobre la ruptura del decoro que supone dar la palabra a un pícaro para que se exprese más allá de los prejuicios que lo encerrarían en el terreno acotado de lo cómico. Sin duda el hecho de plasmar literariamente un personaje de esta

17.- Francisco de Espinosa, Refranero (1527-1547), ed. E. S. O'Kane, RAE, Madrid, 1968.

18.- Juan de Valdés, Diálogo de doctrina christiana y El salterio traducido del hebreo en romance castellano, ed. D.

Ricart, UNAM, México, Madrid, 1964, p. 56.

19.- Doctrina cristiana, p. 20.

20.- Ob. cit., pp. 38-40.

21.- Pedro Ciruelo, Reprobación de las supersticiones y hechicerías, ed. A. V. Ebersole, Albatros, Valencia, 1978, pp. 83-84.

22.- Ob. Cit., p. 80. 


\section{FERNANDO CABO ASEGUINOLAZA}

índole mediante la representación de su palabra implica una ampliación notablemente audaz de las posibilidades de la referencialidad literaria. No sólo porque se trate de pícaros, sino porque, como es sabido, el hacer de uno mismo el tema del relato se enfrentaba de lleno, en la medida en que se alejaba de lo confesional y lo autoinculpatorio, con el inderdicto del «laus propia in ore vilescit». Ya que, como dice el Mellado en el Buscón, «parece mal alabarse el hombre». Y, en efecto, todo relato picaresco, en la medida en que se plantea como autobiográfico, tiene algo de vindicación propia. Pero frente a este reconocimiento, que apunta en efecto a lo que más puede sorprender a primera vista, cabe hacerse una pregunta: ¿,por qué, entonces, la primera persona se utiliza para la representación ficticia de personajes viles y no encontramos el mismo uso ficticio del perspectivismo moderno para el caso aparentemente mucho más propicio de personajes elevados o admirables?

Se aprecia en este aspecto una diferencia en el tratamiento de una realidad socialmente estratificada que no se puede ya asimilar a lo que parece propio de Velázquez; esto es, utilizar el principio del retrato tanto para su criado Juan de Pareja como para el Papa Inocencio IX. De entre las posibles explicaciones que se pudieran plantear quisiera sugerir ahora sólo una, que parte de una triple consideración que remite a elementos bien conocidos. Por un lado, la perogrullada de reconecer que la palabra del pícaro es una palabra dicha por otro y que inevitablemente se convierte en objeto de una valoración particular. Por otra parte toma nota de lo que tanto Peter $\mathrm{N}$. Dunn o Michel Cavillac no han dejado de hacer: esto es, dar cuenta de que la picaresca se sitúa en el comienzo de la época moderna y en relación con profundas modificaciones del sustrato social conectadas de modo directo con la estructuración de la identidad. Y por último se trata de asumir la profundísima incidencia del cauce de presentación impreso, sin el que la picaresca no se entiende, y que favorece, entre otras cosas, la posibilidad de dotar de una mayor apariencia de autonomía al decir sin duda heterónomo del pícaro.

Así las cosas, una de las explicaciones posibles nos lleva una noción que Monique Joly supo sugerir, aunque no la desarrollase hasta sus últimas consecuencias. Me refiero a lo que clla denominó en su artículo sobre las jácaras «discurso directo aberrante» y que presentó como «uno de los rasgos característicos de la representación de la delincuencia» ${ }^{23}$. Podría decirse que se trata del uso de la primera persona, pero no exactamente desde el plano de la expresión propia e individualizada sino desde una caracterización axiológica que es por principio ajena, por no decir hostil, a la que ficticiamente se presenta como origen del discurso. De otra manera, consiste en un discurso directo que constituye a su enunciador, no como un otro, sino como una reificación determinada por la ideología del productor del discurso. De esa manera se prima lo grotesco, y la atribución directa de la palabra se vuelve un mecanismo de invalidación degradante para quien figura como enunciador. Claramente se ve ello en las jácaras y en el tratamiento discursivo que en ellas se ofrece de la figura del delincuente. Y como la propia Joly notó, la carta de Alonso Ramplón a su sobrino es una muestra deslumbrante de esta modalidad, cuyo carácter aberrante depende tanto de su inverosimilitud como de su ilegitimidad desde el punto de vista del decoro.

En su momento ya propuse la consideración del Buscón desde este prisma, aunque advirtiendo que el exhibicionismo cínico de Pablos era por su propia ambición y complejidad formal irreductible a las, llamémosles así, formas simples del discurso directo aberrante. También señalaba entonces que ahí se podría situar, precisamente, la novedad del Buscón con respecto a otros discursos de ese tipo. Creo ahora, sin embargo, que no es ésta una originalidad radical de la obra de Quevedo y que esta particular forma de discurso se halla en el trasfondo de la generalidad de los relatos de pícaros, aunque no siempre planteada de la misma forma ni con la crudeza concentrada de la tradición de la jácara y, en general, de la poesía llamada germanesca.

23.- Monique Joly, "De rufianes, prostitutas y otra carne de horca”, Nueva Revista de Filología Hispánica, XXIX (1980), pp. 1-35, p. 21. Véanse también las interesantes observaciones de Pablo Jauralde, "Enmiendas ideológicas al Buscón", La Perinola, 2 (1998), pp. 87-103, pp. 89-90. 


\section{PALABRA DE PÍCARO: LA REPRESENTACIÓN DISCURSIVA}

Para tratar de explicarlo recurriré por última vez a Ortega. En un punto de sus reflexiones sobre Velázquez se refirió el filósofo madrileño a sus Principios de una nueva Filología, anunciados como uno de los capítulos de Aurora de la razón histórica y que no pasaron de proyecto. En tal lugar se proponían dos leyes pertinentes para toda enunciación, denominadas, con apariencia de contradicción, «ley de la deficiencia» y «ley de la exuberancia». Según la primera, hay siempre una diferencia entre lo que se pretende decir y lo que efectivamente se dice. La expresión, en este sentido, nunca es suficiente ni del todo concorde con la intención. Con la otra ley se apunta al enorme tejido de presuposiciones que implica cualquier expresión, en particular a aquellas que se consideran compartidas de entrada entre el enunciador y su destinatario. Es el terreno de lo consabido, de lo subdicho, en expresión de Ortega, que, a pesar de no ser enunciado de una manera efectiva, sí se manifiesta en lo que se dice, ya sea de una manera deliberada o no.

Hasta podría hacerse una lectura desconstructiva de estos principios orteguianos, pero en este momento lo que nos interesa es que nos ayuden a entender el discurso directo aberrante. Lo fundamental a mi juicio radica en el hecho de que la dimensión exuberante de la enunciación picaresca se fundamenta en presuposiciones que no sólo son ajenas al pícaro como cnunciador -algo del todo natural en una autobiografía ficticia-, sino en la evidencia con que tales supuestos manifiestan su carácter ajeno y, aún más, en el hecho de que entre ellos hay muchos que afectan a la valoración podría decirse que ideológica de la figura que se constituye como narrador y del lenguaje que utiliza.

No se escapa el alcance de todo ello en una situación de redefinición de las identidades, como lo es la modernidad y, muy en particular, el período en el que Velázquez pinta y en el que la picaresca se constituye como serie. Ni tampoco el que muchos de los relatos picarescos, lejos de limitarse a acoger esas valoraciones ajenas, tienen la capacidad de volverse contra ellas en virtud de su peculiar configuración semiótica. Quizá por cllo el estilo picaresco resulte tan heterológico en su conjunto y también posea esa urdimbre entimemática que entrevera la palabra, ya no exclusivamente narrativa, del pícaro de generalizaciones y principios que van situando en un contexto universal las acciones nada espectaculares de estos protagonistas ${ }^{24}$. Se trata de un entramado argumentativo, explícito c implícito, que va dando forma a la palabra del pícaro a la vez que incorpora lo consabido al propio discurso y logra recontextualizarlo, al menos hasta un cierto punto. Creo que es algo muy perceptible en el Buscón, pero también en el Guzmán, quizá sobre todo, y a partir de él en el Guitón y La pícara Justina.

Y también por supuesto en el Lazarillo. Peter N. Dunn se refería a la presencia en él de "essential tropes in the discourse of insolence ${ }^{25}$. Así es. Lázaro se vale continuamente de fórmulas prestigiosas y formulaciones tomadas de lugares que podrían parecer muy alejadas de la situación de discurso correspondiente al pregonero consentidor que resulta ser al final del texto, aunque deba suponerse que tal condición no era ignorada por su destinatario desde el primer momento. En esta perspectiva, el acogerse al entramado de tópicos que todos conocemos puede considerarse efectivamente como una incursión en el terreno de la insolencia, si bien debe admitirse que además de insolente el pregonero resulta muy persuasivo. Pero en todo caso no podría decirse que Lázaro quiera engañar a nadie: de ningún modo estamos ante el discurso de un mentiroso. Más bien resulta de la extraña conformación del discurso lazaresco un entretejido de distancias y valoraciones en acción, que tienen mucho que ver con el principio del retrato.

Y el punto de partida para ello es la conciencia asumida de que la vía de expresión predeterminada para semejante personaje en tal situación sería la del discurso directo abcrrante. Precisamente esa determinación tan perceptible es la que conduce la estrategia retórica que sigue Lázaro, tal como he tratado de explicar en otro lugar ${ }^{26}$. Podría decirse también que el de Lázaro es un discurso

24.- Fernando Cabo Aseguinolaza, "El entimema y el estilo de la picaresca". Edad de Oro, XXIII (2004), pp. 231247.

25.- Ob. cit., p. 93.

26.- "El caso admirable de Lázaro de Tormes: El prólogo del Lazarillo como insinuatio", Bulletin Hispanique, XCVII (1995), pp. 455-464. 


\section{FERNANDO CABO ASEGUINOLAZA}

directo aberrante que se sabe aberrante y trata de jugar con ello para ganar un nuevo ámbito de representación. Aquí, de hecho, podría situarse una de la claves de la cuestión. Un personaje de la índole de los que nos ocupan carece literariamente de un lenguaje propio con el que ser representado, por ello, especialmente cuando se recurre a la primera persona, no puede más que acudirse a otros lenguajes y, como consecuencia, dar lugar a un discurso directo necesariamente aberrante.

El experimento picaresco consiste, pues, en buscar una vía de salida a tal situación. Y esa vía, ligada a una problematización de la identidad social (aunque, como en Quevedo, el punto de partida sea reaccionario), resultará profundamente novedosa. Podría a lo mejor hablarse de realismo, pero siempre que, como Ortega, renunciemos a reducirlo a un estrecho mimetismo y reconozcamos la emergencia de nuevos modos de representación no ajenos del todo a otras modalidades artísticas. 